\title{
CDH1 gene mutations do not contribute in hereditary diffuse gastric cancer in Poland
}

\author{
Anna Jakubowska $\cdot$ Małgorzata Lawniczak $\cdot$ Beata Wojnarska Cezary Cybulski • \\ Tomasz Huzarski • Tomasz Byrski • Aleksandra Tołoczko-Grabarek • \\ Katarzyna Jaworska · Katarzyna Durda · Teresa Starzyńska · Jan Lubiński
}

Published online: 15 September 2010

(c) The Author(s) 2010. This article is published with open access at Springerlink.com

\begin{abstract}
Hereditary diffuse gastric cancer (HDGC) is a cancer susceptibility syndrome characterized by a high risk of diffuse stomach cancer and lobular breast cancer. HDGC is caused by germline mutations in the $\mathrm{CDHl}$ gene encoding the E-cadherin which is a member of the transmembrane glycoprotein family responsible for calciumdependent, cell-to-cell adhesion and plays a fundamental role in the maintenance of cell differentiation and the normal architecture of epithelial tissues. Mutations in the $\mathrm{CDH1}$ gene are detected in $30-46 \%$ of families that fulfil strong clinical criteria for HDGC and in about $11 \%$ of families fulfilling the modified criteria. In the present study, we investigated germline mutations in the $\mathrm{CDH} 1$ gene in Polish patients with HDGC. The entire coding sequence of $\mathrm{CDHl}$ gene was analyzed by sequencing in 86 Polish cancer patients from families fulfilling the modified criteria of HDGC. We found several silent mutations including one common variant (c.2076T $>$ C) present in 56 patients, and three rare variants (c.2253C $>\mathrm{T}, \mathrm{c} .1896 \mathrm{C}>\mathrm{T}$, c. $2634 \mathrm{C}>\mathrm{T}$ ) detected in 2 patients. In addition, we found four rare sequence variants of unknown significance localized in introns. We did not detect any deleterious
\end{abstract}

Anna Jakubowska, Małgorzata Ławniczak authors contributed equally to this publication.

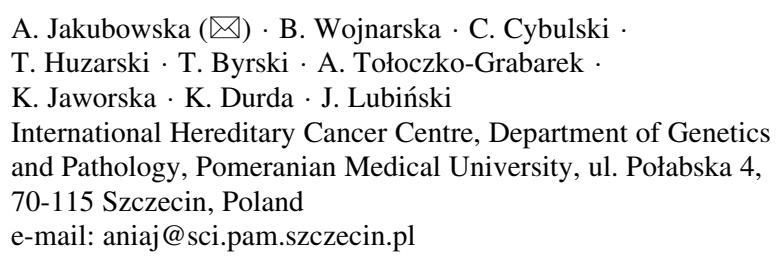

M. Ławniczak · T. Starzyńska Clinic of Gastroenterology Pomeranian Medical University, Szczecin, Poland mutations of the $C D H 1$ gene. $C D H 1$ gene mutations are not present in Polish families with HDGC defined by the modified clinical criteria. Further studies of families with HDGC matching the restrictive criteria for HDGC are needed.

Keywords E-cadherin - Hereditary diffuse gastric cancer . Polish population

$\begin{array}{ll}\text { Abbreviations } \\ \text { CDH1 gene } & \text { E-cadherin gene } \\ \text { IGCLC } & \text { Gastric Cancer Linkage Consortium } \\ \text { HDGC } & \text { Hereditary Diffuse Gastric Cancer } \\ \text { DGC } & \text { Diffuse Gastric Cancer } \\ \text { GC } & \text { Gastric Cancer } \\ \text { LBC } & \text { Lobular Breast Cancer } \\ \text { FDGC } & \text { Familial Diffuse Gastric Cancer } \\ \text { FGC } & \text { Familial Gastric Cancer } \\ \text { EOGC } & \text { Early Onset Gastric Cancer } \\ \text { PCR } & \text { Polymerase Chain Reaction } \\ \text { MRI } & \text { Magnetic Resonance Imaging } \\ \text { HGVS } & \text { Human Genome Variation Society, } \\ & \text { http://www.hgvs.org/ }\end{array}$

Introduction

The E-cadherin is a member of the transmembrane glycoprotein family responsible for calcium-dependent, cellto-cell adhesion and plays a fundamental role in the maintenance of cell differentiation and the normal architecture of epithelial tissues [1-7]. The protein is encoded by the CDHI gene which is located on chromosome $16 \mathrm{q} 22.1$ and consists of 16 exons. Mutations in $\mathrm{CDH1}$ gene 
are known to be associated with Hereditary Diffuse Gastric Cancer syndrome (HDGC) [8-16] and also with lobular breast cancer [17-19]. The HDGC has been defined in 1999 by International Gastric Cancer Linkage Consortium (IGCLC) as two or more documented cases of DGC in first or second degree relatives, including at least one case of DGC diagnosed before the age of 50 , or three or more documented cases of DGC in first or second degree relatives diagnosed at any age $[9,10]$. Among patients that fulfill the above clinical criteria about $30-46 \%$ of cases carry a mutation in the $C D H 1$ gene $[11,15,20-22]$. Afterwards the IGCLC criteria have been modified e.g. including cases diagnosed with lobular breast cancer or signet-ring carcinoma of the colon [12]. The new modified criteria were as follow: (1) two or more documented cases of DGC in first-degree relatives with at least one diagnosed before age 50 years; (1A) two or more cases of GC with at least 1 documented DGC diagnosed before age 50 years; (2) three or more documented cases of DGC in first-degree relatives with diagnoses at any age; (2A) three or more cases of GC, diagnosed at any age, with at least one documented case of DGC; (3) isolated individual diagnosed with DGC at less than 45 years of age; (4) isolated individual diagnosed with both DGC and lobular breast cancer (no other criteria met); (5) one family member diagnosed with DGC and another with lobular breast cancer (no other criteria met); (6) one family member diagnosed with DGC and another with signet-ring carcinoma of the colon (no other criteria met). It has been shown that among patients fulfilling the modified criteria $11 \%$ carry $\mathrm{CDHI}$ mutation [12-14].

Patients with germline mutations in the $C D H I$ have a high risk of developing diffuse gastric cancer and female carriers are at high risk of lobular breast cancer [17-19]. The estimated penetrance of $C D H 1$ mutations is $70-80 \%$ for stomach cancer $[8,15,22,23]$ and $39-52 \%$ for lobular breast cancer $[15,23]$. Because of high penetrance of CDH1 mutations and almost $100 \%$ mortality of patients with symptomatic DGC prophylactic total gastrectomy during the second decade of life is recommended for $\mathrm{CDH} 1$ mutation carriers [22, 24-26]. Referring to updated consensus guidelines for clinical management of HDGC in female carriers surveillance including monthly breast self examination starting at age 35 , annual mammogram and breast MRI is recommended [26]. Additionally, in families in which colon cancer was reported enhanced screening with colonoscopy beginning at age 40 or 10 years younger than the youngest diagnosis of colon cancer and repeated at intervals of 3-5 years should be considered [26].

Given the complexity and high mortality of HDGC, not only with regard to the management of the DGC, but also with regard to the risk for other related cancers such as lobular breast cancer or colon cancer, it is very important to identify asymptomatic carriers of $\mathrm{CDH} 1$ mutations in order to apply the appropriate surveillance.

In the current study we sought to determine prevalence of $\mathrm{CDH} 1$ mutations in Polish families with diffuse gastric cancer.

\section{Materials and methods}

\section{Patients}

For analysis of $\mathrm{CDH1}$ gene 86 Polish patients from families fulfilling the modified criteria of HDGC were selected. Among these cases 82 were affected by DGC, two cases were diagnosed with lobular breast cancer and two with colon cancer. Only families with GC diagnosed in first and second degree relatives were included to this study. The characteristic of tested families including mean age at stomach cancer diagnosis is presented in the Table 1.

Patients were invited to participate in this study either in person during their hospital stay in participating hospitals throughout Poland or through a mailed invitation. Patients who responded to the personal or mailed invitation were invited to the local study center for an interview. During the interview the goals of the study were explained, informed consent was obtained, genetic counseling was given and a blood sample was taken for DNA analysis. A detailed family history of gastric cancer in first- and second-degree relatives was taken and the medical record and/or pathology report were reviewed and forwarded to the study center in Szczecin. Information was recorded on age at diagnosis and cancer pathology. The study was approved by the Ethics Committee of the Pomeranian Medical University in Szczecin, Poland.

\section{Sequencing}

Peripheral blood samples from 86 probands were obtained for genomic DNA isolation. DNA was isolated using a standard procedure [27]. The entire coding sequence of $\mathrm{CDH} 1$ gene and intron/exon splice sites, was amplified in PCR reactions using primers and conditions described previously [16]. After purification, PCR products were analysed on an ABI 377 DNA Sequencer according to manufacturer's procedure.

\section{Results and discussion}

This is the first study of $\mathrm{CDH} 1$ mutations in the Polish population, in which we screened 86 patients with HDGC. We found four different silent mutations: one common (c.2076T $>$ C) and three rare (c.2253C $>$ T, c.1896C $>$ T, 


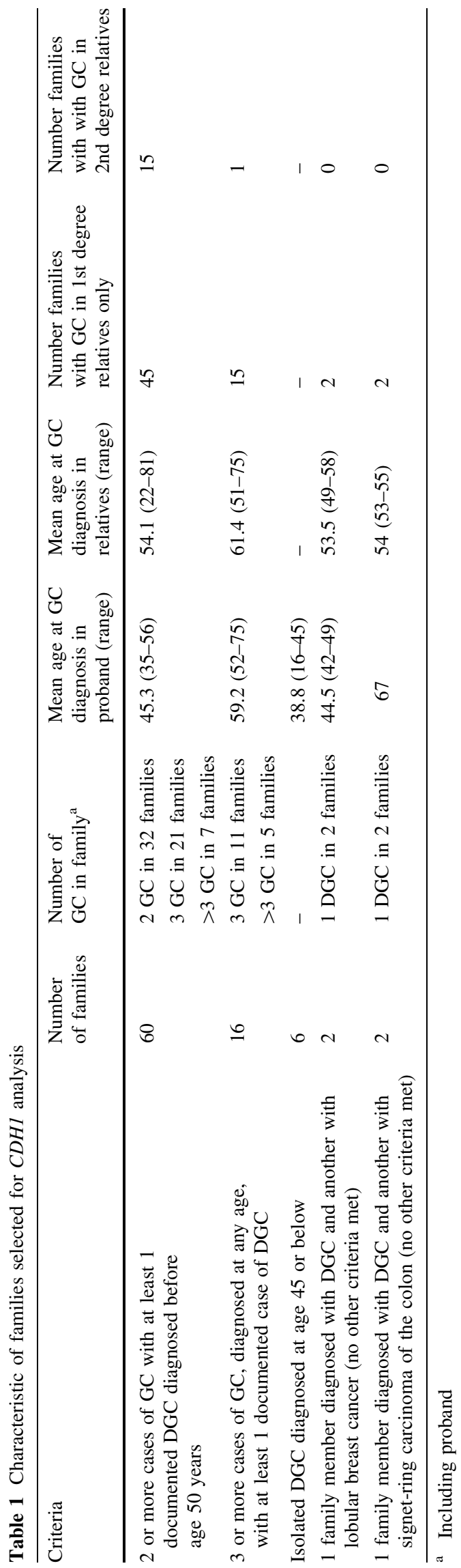

Table $2 \mathrm{CDH} 1$ variants detected in 86 Polish patients with HDGC

\begin{tabular}{ll}
\hline$C D H 1$ variant $^{\mathrm{a}}$ & Number of carriers \\
\hline c. $1896 \mathrm{C}>\mathrm{T}(\mathrm{p} .=)$ & $1^{\mathrm{b}}$ \\
c. $2076 \mathrm{~T}>\mathrm{C}(\mathrm{p} .=)$ & 56 \\
c. $2253 \mathrm{C}>\mathrm{T}(\mathrm{p} .=)$ & 1 \\
c. $2634 \mathrm{C}>\mathrm{T}(\mathrm{p} .=)$ & $1^{\mathrm{b}}$ \\
c. $1-44 \mathrm{~A} / \mathrm{G}$ & 7 \\
c. $172+6 \mathrm{~T} / \mathrm{C}$ & 11 \\
c. $655+10 \mathrm{C} / \mathrm{G}$ & 2 \\
c. $1836-46 \mathrm{~A} / \mathrm{G}$ & 1 \\
c. $1836-13 \mathrm{~T} / \mathrm{C}$ & 14
\end{tabular}

a Description of detected variants according to the HGVS recommendations; $(\mathrm{p} .=)$ indicates lack of effect on protein level-silent mutation

b Patient with both detected variants

c. $2634 \mathrm{C}>\mathrm{T}$ ) variants. In addition, we found five different sequence variants of unknown significance localized in introns (Table 2). We did not detect any pathogenic mutations in the $\mathrm{CDH} 1$ gene.

Germline mutations in $\mathrm{CDHI}$ gene were originally reported in three Maori families with aggregation of diffuse gastric cancer [8]. Since this report, several studies have investigated the role of $\mathrm{CDH} 1$ mutations in gastric cancer in different ethnic groups [8-22]. It has been reported that CDH1 mutations underlie approximately $40 \%$ of families fulfilling the strong IGCLC criteria for hereditary diffuse gastric cancer (HDGC). However, the criteria for HDGC defined by IGCLC require strong family history with all documented cases of diffuse gastric cancer what refers to small number of all patients affected with gastric cancer. Therefore, $\mathrm{CDH} 1$ gene has been screened in gastric cancer patients fulfilling less restrictive, modified criteria of familial diffuse gastric cancer (FDGC-families with aggregation of gastric cancer and index cases with diffuse gastric cancer but not fulfilling the IGCLC criteria for HDGC), familial gastric cancer (FGC-families with aggregation of gastric cancer, but without histology available on the tumors) and early-onset gastric cancer (EOGC-patients with isolated diffuse gastric cancer diagnosed before age 45 years) [9]. CDH1 mutations have been found in $11 \%$ (21/192) of families with FDGC and almost 7\% (17/254) of patients with EOGC [11].

In the present study we screened a relatively large series of 86 cases with HDGC fulfilling the modified criteria (FDGC, EOGC), but we did not find any pathogenic mutations in the $\mathrm{CDHl}$ gene. We performed a sensitive exon by exon sequencing of the entire gene including surrounding intronic sequences. With this method we are able to detect all small intragenic mutations which are the most common mutations observed in the $\mathrm{CDH} 1$ gene [8-22]. 
Recently large genomic deletions in $\mathrm{CDH} I$ gene have been found in patients from HDGC families. In the study of 160 patients from families fulfilling the restrictive criteria HDGC $67(42 \%)$ point or small frameshift mutations and 6 (4\%) large genomic deletions in $\mathrm{CDH} 1$ gene were detected [20]. This indicates that large genomic rearrangements constitute only a small proportion of $\mathrm{CDHI}$ mutations $(\sim 8 \%)$. It is unlikely that the negative result of our study is due to low sensitivity of methods used for mutation screening.

In summary, results of our study show that $\mathrm{CDH} 1$ mutations do not contribute to diffuse gastric cancer in Poland, however, taking into account limitations of our study which are: less restrictive criteria of gastric cancer patients selection and lack of analysis for large genomic deletions, further studies of HDGC in Polish population are needed.

Acknowledgments The study was supported by Grant PBZ-KBN090/P05/2003

Open Access This article is distributed under the terms of the Creative Commons Attribution Noncommercial License which permits any noncommercial use, distribution, and reproduction in any medium, provided the original author(s) and source are credited.

\section{References}

1. Takeichi M (1995) Morphogenetic roles of classic cadherins. Curr Opin Cell Biol 7(5):619-627

2. Moriyama N, Ishihara S, Hirose M et al (2001) E-cadherin is essential for gastric epithelial restitution in vitro: a study using the normal rat gastric mucosal cell line RGM1. J Lab Clin Med 138(4):236-242

3. Del Buono R, Pignatelli M (1999) The role of the E-cadherin complex in gastrointestinal cell differentiation. Cell Prolif 32(2-3):79-84

4. Handschuh G, Candidus S, Luber B et al (1999) Tumour-associated E-cadherin mutations alter cellular morphology, decrease cellular adhesion and increase cellular motility. Oncogene 18(30):4301-4312

5. Mayer B, Johnson JP, Leitl F et al (1993) E-cadherin expression in primary and metastatic gastric cancer: down-regulation correlates with cellular dedifferentiation and glandular disintegration. Cancer Res 53(7):1690-1695

6. Christofori G, Semb H (1999) The role of the cell-adhesion molecule E-cadherin as a tumour-suppressor gene. Trends Biochem Sci 24(7):73-76

7. Vleminckx K, Vakaet L Jr, Mareel M et al (1991) Genetic manipulation of E-cadherin expression by epithelial tumor cells reveals an invasion suppressor role. Cell 66(1):107-119

8. Guilford P, Hopkins J, Harraway J et al (1998) E-cadherin germline mutations in familial gastric cancer. Nature 392(6674): 402-405

9. Caldas C, Carneiro F, Lynch HT et al (1999) Familial gastric cancer: overview and guidelines for management. J Med Genet 36(12):873-880
10. Guilford P, Hopkins JB, Grady WM et al (1999) E-cadherin germline mutations define an inherited cancer syndrome dominated by diffuse gastric cancer. Hum Mutat 14(3):249-255

11. Pedrazzani C, Corso G, Marrelli D, Roviello F (2007) E-cadherin and hereditary diffuse gastric cancer. Surgery 142(5):645-657

12. Brooks-Wilson AR, Kaurah P, Suriano G et al (2004) Germline E-cadherin mutations in hereditary diffuse gastric cancer: assessment of 42 new families and review of genetic screening criteria. J Med Genet 41(7):508-517

13. Suriano G, Yew S, Ferriera P et al (2005) Characterization of a recurrent germ line mutation of the E-cadherin gene: implications for genetic testing and clinical management. Clin Cancer Res 11(15):5401-5409

14. More H, Humar B, Weber W et al (2007) Identification of seven novel germline mutations in the human E-cadherin (CDH1) gene. Hum Mutat 28(2):203

15. Kaurah P, MacMillan A, Boyd N et al (2007) Founder and recurrent $\mathrm{CDH} 1$ mutations in families with hereditary diffuse gastric cancer. JAMA 297(21):2360-2372

16. Gayther SA, Gorringe KL, Ramus SJ et al (1998) Identification of germ-line E-cadherin mutations in gastric cancer families of European origin. Cancer Res 58:4086-4089

17. Masciari S, Larsson N, Senz J et al (2007) Germline E-cadherin mutations in familial lobular breast cancer. J Med Genet 44(11): 726-731

18. Schrader KA, Masciari S, Boyd N et al (2008) Hereditary diffuse gastric cancer: association with lobular breast cancer. Fam Cancer 7(1):73-82

19. Keller G, Vogelsang H, Becker I et al (1999) Diffuse type gastric and lobular breast carcinoma in a familial gastric cancer patient with an E-cadherin germline mutation. Am J Pathol 155(2): 337-342

20. Oliveira C, Senz J, Kaurah P et al (2009) Germline CDH1 deletions in hereditary diffuse gastric cancer families. Hum Mol Genet 18(9):1545-1555

21. Guilford P, Humar B, Blair V (2010) Hereditary diffuse gastric cancer: translation of $\mathrm{CDH} 1$ germline mutations into clinical practice. Gastric Cancer 13(1):1-10

22. Lynch HT, Grady W, Suriano G, Huntsman D (2005) Gastric cancer: new genetic developments. J Surg Oncol 90(3):114-133

23. Pharoah PD, Guilford P, Caldas C, International Gastric Cancer Linkage Consortium (2001) Incidence of gastric cancer and breast cancer in CDH1 (E-cadherin) mutation carriers from hereditary diffuse gastric cancer families. Gastroenterology 121(6):13481353

24. Guilford P, Blair V, More H, Humar B (2007) A short guide to hereditary diffuse gastric cancer. Hered Cancer Clin Pract 5(4): 183-194

25. Blair V, Martin I, Shaw D et al (2006) Hereditary diffuse gastric cancer: diagnosis and management. Clin Gastroenterol Hepatol 4(3):262-275

26. Fitzgerald RC, Hardwick R, Huntsman D et al (2010) Hereditary diffuse gastric cancer: updated consensus guidelines for clinical management and directions for future research. J Med Genet 47(7):436-444

27. Lahiri DK, Schnabel B (1993) DNA isolation by rapid method from human blood samples: effects of $\mathrm{MgCl} 2$, EDTA, storage time, and temperature on DNA yield and quality. Biochem Genet 31(7-8):321-328 